\title{
Inhibitory Potential of Thelephoric Acid on CYP2J2 Activities in Human Liver Microsomes
}

\author{
Zhexue Wu', Boram Lee ${ }^{\dagger}$, Kyung-Sik Song, Kwang-Hyeon Liu* \\ College of Pharmacy and Research Institute of Pharmaceutical Sciences, Kyungpook National University, Daegu 702-701, Korea
}

Received September 12, 2013 /Revised September 15, 2013 / Accepted September 25, 2013

\begin{abstract}
Cytochrome P450 2J2 (CYP2J2) is an enzyme mainly found in human extrahepatic tissues, with predominant expression in the cardiovascular system. CYP2J2 plays important roles in the metabolism of endogenous metabolites and therapeutic drugs, such as arachidonic acid, astemizole, ebastine, and terfenadine. CYP2J2 is also overexpressed in human cancer tissues and cancer cell lines and may represent a potential target for therapy of human cancers. In this study, 10 natural products obtained from plants and microorganisms were screened as potential CYP2J2 inhibitors. Among them, thelephoric acid showed strong inhibition of astemizole $O$-demethylation activity $\left(\mathrm{IC}_{50}=3.23 \mu \mathrm{M}\right)$ in a dose-dependent manner. Evaluation of the substrate dependency of the inhibitory activity of thelephoric acid showed that it strongly inhibited CYP2J2-mediated ebastine hydroxylation $\left(\mathrm{IC}_{50}=5.32 \mu \mathrm{M}\right)$ and terfenadine hydroxylation $\left(\mathrm{IC}_{50}=3.27 \mu \mathrm{M}\right)$ in a substrate nondependent manner. The present data suggest that this compound might be a potential candidate for further evaluation for anticancer activity.
\end{abstract}

Key words : Thelephoric acid, CYP2J2, screening, drug-interaction, cytochrome P450

\section{서 론}

Cytochrome P450 2J2 (CYP2J2)는 인체에서 존재하는 유일 한 CYP2J subfamily 동효소로써, 다른 시토크롬 P450 효소와 는 달리 심장에서 과발현되는 효소로 알려져 있고, 이외에도 소장이나 간, 신장, 대장, 췌장 및 폐 등에도 소량 분포하는 것으로 보고되었다[23]. CYP2J2는 아라키돈산의 에폭시에이 코사트리에논산(epoxyeicosatrienoic acid, EET)으로의 대사 등과 같은 내인성 물질의 대사에 관여함으로써 인체의 항상성 유지에 관여하고 있다. 또한 사이클로스포린(cyclosporin), 아 미오다론(amiodarone), 아스테미졸(astemizole), 아픽사반 (apixaban), 알벤다졸(albendazole), 에바스틴(ebastine), 타목 시펜(tamoxifen), 터페나딘(terfenadine), 티오리다진(thioridazine), 및 펜벤다졸(fenbendazole)과 같은 약물의 대사에 관 여하는 것으로 알려져 있다 $[8,11,13,19,20,22,23]$. CYP2J2의 작용에 의해 아라키돈산으로부터 생성된 $\mathrm{EET}$ 는 생체막의 이 온수송능력을 조절하고 펩타이드 호르몬의 유리를 변화시키 며, 기도의 평활근에도 영향을 준다. 그 밖에도 항염증, 신장

\footnotetext{
${ }^{\dagger}$ Authors contributed equally.

*Corresponding author

Tel : +82-53-950-8567, Fax : +82-53-950-8557

E-mail : dstlkh@knu.ac.kr

This is an Open-Access article distributed under the terms of the Creative Commons Attribution Non-Commercial License (http://creativecommons.org/licenses/by-nc/3.0) which permits unrestricted non-commercial use, distribution, and reproduction in any medium, provided the original work is properly cited.
}

기능 조절, 혈압 조절, 혈소판 응집 억제 등과 같은 다양한 생물학적 활성을 가지고 있다[1, 9, 12, 14, 16-18, 21, 25].

한편, 최근 연구에서 CYP2J2가 인제 종양 조직 및 종양 세 포에서 과발현되어 있음이 보고되어 왔다[2, 3]. 이 연구에서 CYP2J2가 종양 조직 주위의 정상조직 및 정상세포에서는 거 의 발견되지 않음이 확인되었고, CYP2J2의 발현을 증가시키 거나, CYP2J2의 대사산물인 EET를 배양중인 암세포주에 첨가 할 경우 암세포의 증식이 증가하는 것이 확인되었다[2, 3]. 이 러한 연구 결과는 CYP2J2 매개 EET 생합성의 억제가 종양 치료에 대한 새로운 접근 방식이 될 수 있음을 시사한다[5].

본 연구에서는, CYP2J2 효소 활성에 저해능을 보이는 화합 물을 발굴하기 위하여 10 종의 천연물을 대상으로 CYP2J2의 기질 약물인 아스테미졸로부터 생성되는 CYP2J2 매개 대사체 인 $O$ desmethyl astemizole의 생성 속도를 측정함으로써 인체 CYP2J2 효소 활성 저해능을 평가하고자 하였다[13]. 또한, 10 종 천연물의 CYP2J2 효소 활성도 억제 연구를 통하여 강한 저해능을 보인 thelephoric acid 에 대하여, CYP2J2의 또 다른 기질 약물인 ebastine 및 terfenadine 으로 부터 생성되는 CYP2J2 매개 대사체인 hydroxyebastine 및 terfenadine alcohol의 생성 속도를 측정함으로써, telephoric acid의 CYP2J2 저해 활성에 대한 기질 특이성을 규명하고자 하였다[24].

\section{재료 및 방법}

시약 및 재료

CYP2J2 효소 활성 측정에 필요한 CYP2J2 기질약물 및 대사 체인 astemizole, $O$-desmethyl astemizole, ebastine, hydrox- 
yebastine 및 terfenadine은 Toronto Research Chemical (North York, Canada)에서 구매하여 사용하였다. NADP ${ }^{+}$, glucose-6-phosphate, 및 glucose-6-phosphate dehydrogenase은 Sigma-Aldrich (St. Louis, MO)에서 구매하였고, 및 CYP2J2 효소 활성 저해능 평가를 위한 천연물 10종은(Fig. 1) 한국한방산업진홍원에서 분양받아 사용하였다. 인체 간 마이
크로솜(H161)과 terfenadine alcohol은 BD Gentest (Woburn, $\mathrm{MA})$ 에서 구입하였다. 기타 본 연구에 이용된 시약은 모두 실 험에 이용 가능한 최상급을 구입하여 사용하였다.

천연물 스크리닝을 통한 CYP2J2 활성 저해제 탐색 10 종 천연물의 CYP2J2 효소 활성도 억제에 대한 연구는<smiles>O=C1c2oc3cc(O)c(O)cc3c2C(=O)c2oc3cc(O)c(O)cc3c21</smiles>

Thelephoric acid<smiles>COc1cc([C@H]2c3cc4c(cc3C[C@H]3COC(=O)[C@H]23)OCO4)cc(OC)c1OC</smiles>

Anthricin<smiles>CC1=C[C@H](O)[C@H]2C(C1=O)C2(C)C</smiles>

Asarinol A<smiles>Nc1nc(=O)[nH]c2c1ncn2[C@@H]1O[C@H](CO)[C@@H](O)[C@H]1O</smiles>

Crotonoside

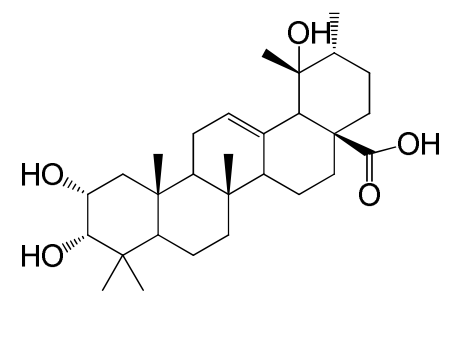

Euscaphic acid<smiles>COc1cc2c(cc1O)CCN1C=Cc3cc(OC)c(OC)cc3CN(CC1)C2</smiles>

Jatrorrhizine

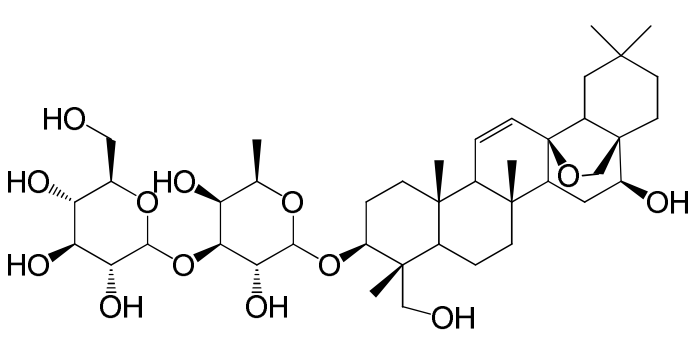

Saikosaponin A

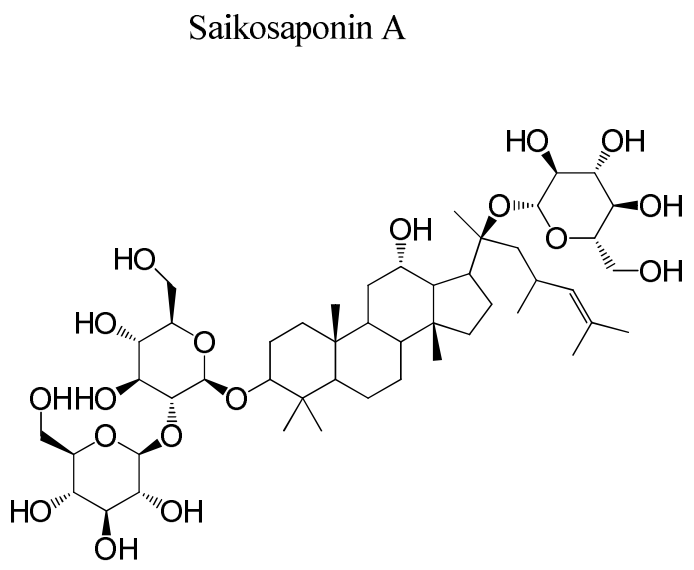

Ginsenoside Rd

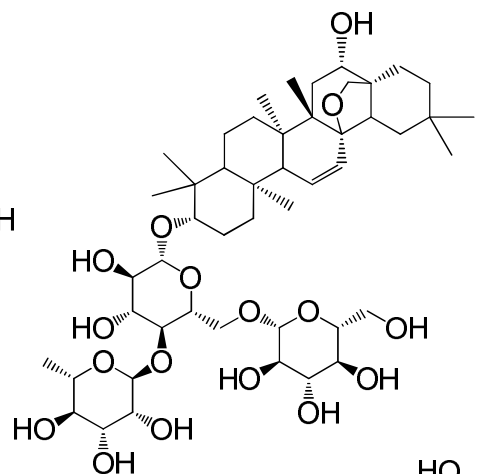

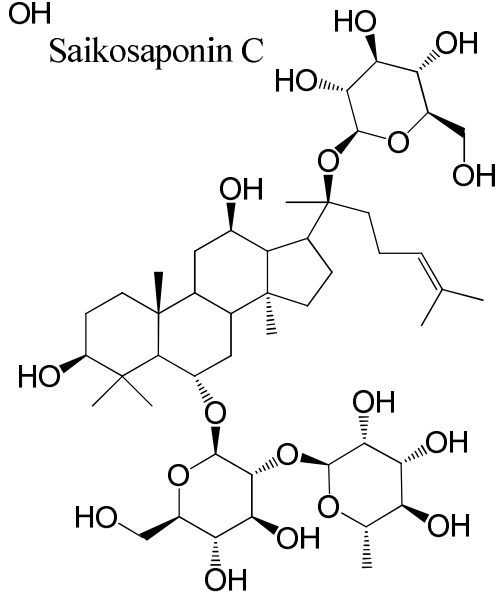

Ginsenoside Re

Fig. 1. Chemical structures of ten natural products used in this study. 
CYP2J2의 기질 약물인 astemizole 로부터 생성되는 CYP2J2 매개 대사체인 $O$ desmethyl astemizole의 생성 속도를 측정함 으로써 평가하였다 $[9,24]$. 즉, astemizole $(1 \mu \mathrm{M})$ 만을 혹은 astemizole과 함께 억제제로 천연물 $(5 \mu \mathrm{g} / \mathrm{ml})$ 을 $0.1 \mathrm{mg} / \mathrm{ml}$ 의 인체 마이크로솜을 함유하고 있는 $500 \mathrm{mM}$ 인산 완충액(pH $7.4)$ 에 넣고 $37^{\circ} \mathrm{C}$ 에서 5 분간 배양하였다. 이후 $\mathrm{NADPH}$ 재생성 계(1.3 mM NADP ${ }^{+}, 3.3 \mathrm{mM} \mathrm{G} 6 \mathrm{P}, 3.3 \mathrm{mM} \mathrm{MgCl}$, 및 500 unit/ml G6PDH)를 첨가함으로써 반응을 시작하였고, 20분간 의 반응 후 내부표준물질로서 $100 \mathrm{nM}$ mebendazole을 포함하 고 있는 아세토니트릴(acetonitrile) $50 \mu \mathrm{l}$ 를 첨가하여 반응을 정지시켰다. 반응정지 후, 원심분리기에서 5 분간 원심분리 $(14,000 \times g)$ 한 후 상층액을 직접 LC-MS/MS 시스템에 주입하 였다.

\section{Thelephoric acid의 CYP2J2 저해능 평가}

10 종 천연물의 CYP2J2 효소 활성도 억제 연구를 통하여 강한 저해능을 보인 thelephoric acid에 대하여, CYP2J2 활성 억제 상수 $\left(\mathrm{IC}_{50}\right)$ 를 구하는 실험을 수행하였다. 즉, CYP2J2의 기질 약물인 astemizole, ebastine 및 terfenadine으로 부터 생 성되는 CYP2J2 매개대사체인 $O$-desmethyl astemizole, hydroxyebastine 및 terfenadine alcohol의 생성 속도를 측정하 여 억제상수를 측정하였다 $[8,9,11,13,24]$. 3종의 CYP2]2 기질 약물 중 하나만을 $(1 \mu \mathrm{M}$ astemizole, $1 \mu \mathrm{M}$ ebastine, 또는 5 $\mu \mathrm{M}$ terfenadine) 혹은 기질약물 한 종과 함께 억제제로 thelephoric acid $(0 \sim 20 \mu \mathrm{M})$ 을 같이 $0.1 \mathrm{mg} / \mathrm{ml}$ 의 인체 마이크로솜 을 함유하고 있는 $500 \mathrm{mM}$ 인산완충액 $(\mathrm{pH} 7.4)$ 에 넣고 $37^{\circ} \mathrm{C}$ 에 서 5 분간 배양하였다. 이후 NADPH 재생성계를 첨가함으로 써 반응을 시작하고, 20 분간의 반응 후 내부표준물질 $(300 \mathrm{nM}$ mebendazole)을 포함하고 있는 아세토니트릴 $50 \mu 1$ 를 첨가하 여 반응을 정지시켰다. 반응 정지 후, 원심분리기에서 5 분간 원심분리 $(14,000 \times g)$ 한 후 상층액을 직접 LC-MS/MS 시스템 에 주입하였다.

\section{$\mathrm{LC}-\mathrm{MS} / \mathrm{MS}$ 분석}

$O$-Desmethyl astemizole, hydroxyebastine, terfenadine alcohol 및 mebendazole (내부표준물질)을 분리하기 위해 Phenomenex 사의 Luna C18 컬럼 $(2 \times 50 \mathrm{~mm}, 3 \mu \mathrm{m})$ 을 사용하 였고, 이동상은 $0.1 \%$ formic acid를 첨가한 물(이동상 $\mathrm{A}$ ) 및 아세토니트릴(이동상 B)를 사용하였다. O-Desmethyl astemizole은 $30 \%$ B 등용매(isocratic) 조건에서 분석하였고, hydrox- yebastine 및 terfenadine alcohol은 0 분에서 6 분 사이에 이동 상 $\mathrm{B}$ 조성을 $10 \%$ 에서 $50 \%$ 로 증가시킨 후, 6.1 분에 이동상 $\mathrm{B}$ 조성을 $10 \%$ 로 감소시킨 후 10 분까지 유지하면서 분석을 수행하였다(Fig. 2). 이 때 이동상의 유속은 $0.2 \mathrm{ml} / \mathrm{min}$ 으로 유지하였으며, 탠덤질량분석기(Shimadzu 8040 LC-MS/MS system, Shimadzu, Tokyo, Japan)를 이용하여 검출하였다. 탠 덤질량분석시 이온소스는 전기분무 이온화법(electrospray ionization, positive mode)을 사용하였고, 이온화 전압은 4 $\mathrm{kV}$, 탈용매화 온도는 $300^{\circ} \mathrm{C}$ 로 조정하였다. 질소가스 흐름 속 도의 분무가스는 $3 \mathrm{l} / \mathrm{min}$, 커튼가스는 $2.0 \mathrm{Arb}$, 보조가스는 $10 \mathrm{Arb}$ 으로, 건조 가스는 $8 \mathrm{l} / \mathrm{min}$ 으로 조정하였고, 충돌가스 (아르곤) 에너지 값(collision energy)은 $35 \mathrm{eV}(O$-desmethyl astemizole), $42 \mathrm{eV}$ (hydroxyebastine), $36 \mathrm{eV}$ (terfenadine alcohol), 및 $17 \mathrm{eV}$ (mebendazole) 이었다(Table 1). 분석 물질의 정량을 위하여 SRM (selected reaction monitoring) 정량 모드 를 이용하였고, $O$-desmethyl astemizole, hydroxyebastine, terfenadine alcohol, mebendazole 의 선택 질량으로서는 각각 $m / 2445>204,486>167,488>452$, 및 296>264로 양이온 모드에 서 측정하였다(Table 1).

\section{데이터 해석}

CYP2J2 동효소에 특이한 기질 약물로부터 대사체 생성에 대한 저해제의 CYP2J2 활성 억제에 대한 경수( $\left(\mathrm{IC}_{50}\right)$ 는, 스크리 닝 단계에서 저해능을 보인 화합물 thelephoric acid의 농도를 달리하면서 $(0 \sim 20 \mu \mathrm{M})$, 효소 활성 저해 연구를 수행 후 약동학 분석 프로그램인 WinNonlin (version 2.0, Pharsight, Apex)을 이용하여 비선형 최소자승 회귀분석법을 이용하여 산출하였 다.

\section{결과 및 고찰}

지난 15 년 동안, CYP2J2 동효소는 아라키돈 산 대사능인 epoxygenase 활성에 대해 많은 관심을 받아 왔다. 그러나, 최 근 CYP2J2 단백질이 정상조직에 비해 종양조직에 과발현되어 있음이 보고된 이후, CYP2J2 단백을 표적으로 하는 표적 항암 제에 대한 연구가 일부 연구자에 의해 활발히 진행되고 있다 $[2-5,15,26]$. Lafite 등은 CYP2J2 효소 활성에 강한 저해능을 보이는 terfenadone 유도체를 발굴하였으며 [6, 7], 윤 등은 에 바스틴의 대사체인 hydroxyebastine 이 강력한 CYP2J2 동효 소 활성 저해능을 가지고 있음을 보고한 바 있다[10, 24]. 또한

Table. 1 Mass operation parameters for the analysis of CYP2J2-mediated metabolites of astemizole, ebastine, and terfenadine

\begin{tabular}{lclccc}
\hline Substrate & Concentration $(\mu \mathrm{M})$ & Metabolite & Transition $(m / 2)$ & Polarity & Collision energy $(\mathrm{eV})$ \\
\hline Astemizole & 1 & O-Desmethyl astemizole & $445>204$ & ESI $^{+}$ & 35 \\
Ebastine & 1 & Hydroxyebastine & $486>167$ & ESI $^{+}$ & 42 \\
Terfenadine & 5 & Terfenadine alcohol & $488>452$ & ESI $^{+}$ & 36 \\
Mebendazole (IS) & & & $296>264$ & ESI $^{+}$ & 17 \\
\hline
\end{tabular}


A

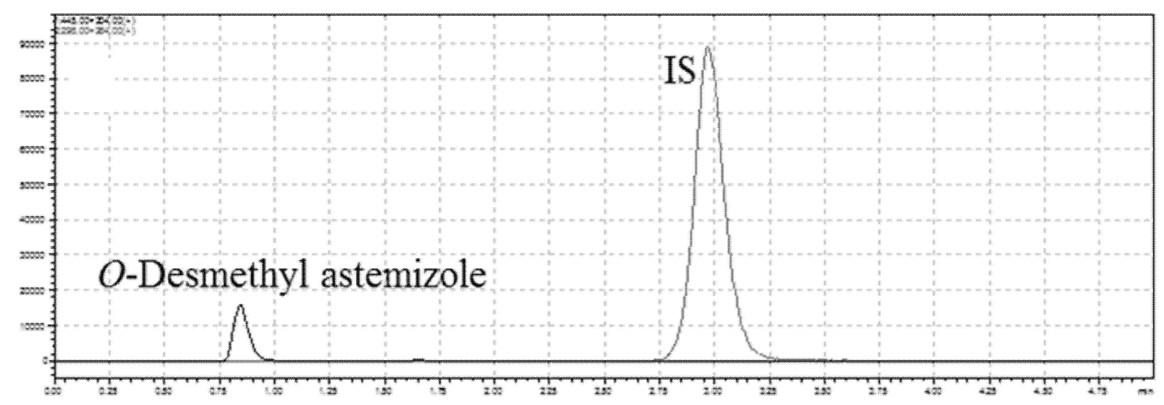

B

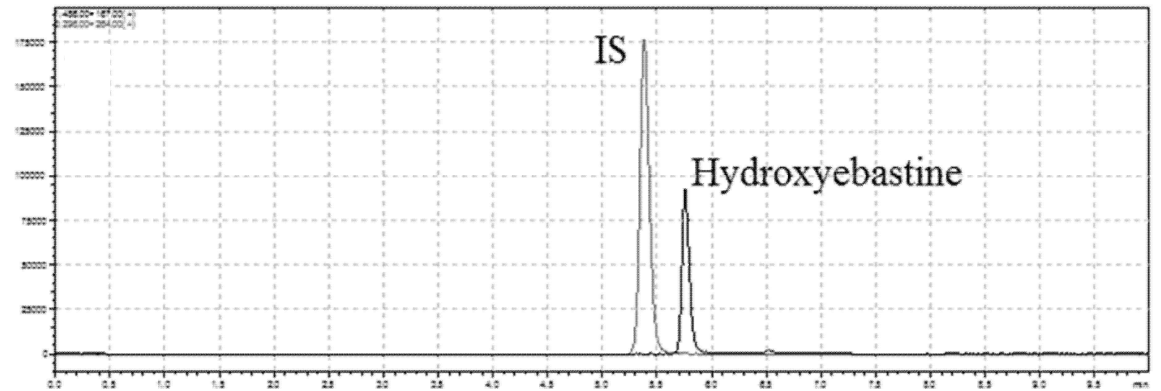

C

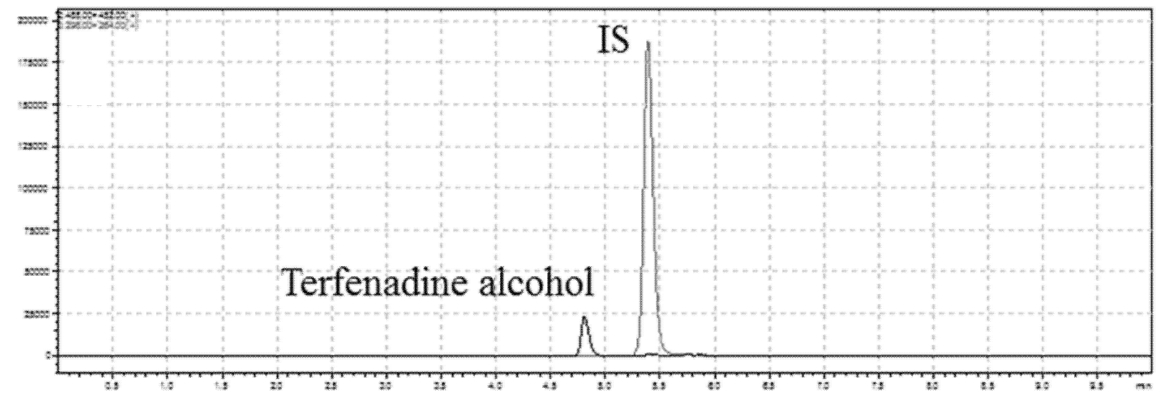

Fig. 2. LC-MS/MS total ion chromatograms of $O$-desmethyl astemizole (A), hydroxyebastine (B), terfenadine alcohol (C), and mebendazole (IS) from in vitro incubation with human liver microsomes. Astemizole (A), ebastine (B), or terfenadine (C) was incubated with human liver microsomes $(0.1 \mathrm{mg} / \mathrm{ml})$ in the presence of $\mathrm{NADPH}$-generating system for $20 \mathrm{~min}$ at $37^{\circ} \mathrm{C}$.

Chen 등은 terfenadine 유도체의 종양세포 증식 억제 및 세포 사멸 기전을 규명하였다[2, 4]. 그러나, 현재까지 CYP2J2 효소 활성을 억제한다고 알려진 물질은 terfenadone 유도체, hydroxyebastine, miconazole을 포함하여 일부에 불과한 실정이 다 $[6,7,11,24]$. 따라서, 본 연구에서는 식물 및 미생물에서 분리된 화합물을 대상으로 인체 CYP2J2 효소 활성에 저해능 을 보이는 화합물을 발굴함으로써, 표적 항암제 후보물질 개 발에 이용될 수 있는 유효물질(Hit)을 도출하고자 하였다. 천 연물 10종을 대상으로 CYP2J2 동효소 저해 활성을 평가한 결 과, $5 \mathrm{\mu g} / \mathrm{ml}$ 농도에서 thelephoric acid 가 O-desmethyl astemizole 형성을 $70 \%$ 이상 저해하는 것으로 나타났다(Fig. 3).

또한, thelephoric acid의 CYP2J2 효소 저해 활성에 대한 기질특이성을 조사하기 위하여, CYP2J2의 다른 기질약물인 ebastine 및 terfenadine을 대상으로 CYP2J2 효소 활성 저해능 을 재평가하였다. 그 결과, astemizole 에서 가장 큰 저해능 $\left(\mathrm{IC}_{50}=3.23 \mu \mathrm{M}\right)$ 을 보였던 thelephoric acid는 CYP2J2 매개 terfenadine 대사 $\left(\mathrm{IC}_{50}=3.27 \mu \mathrm{M}\right)$ 및 ebastine 대사 $\left(\mathrm{IC}_{50}=5.32 \mu \mathrm{M}\right)$ 를 유사하게 억제하는 것으로 나타났다(Table 2, Fig. 4).

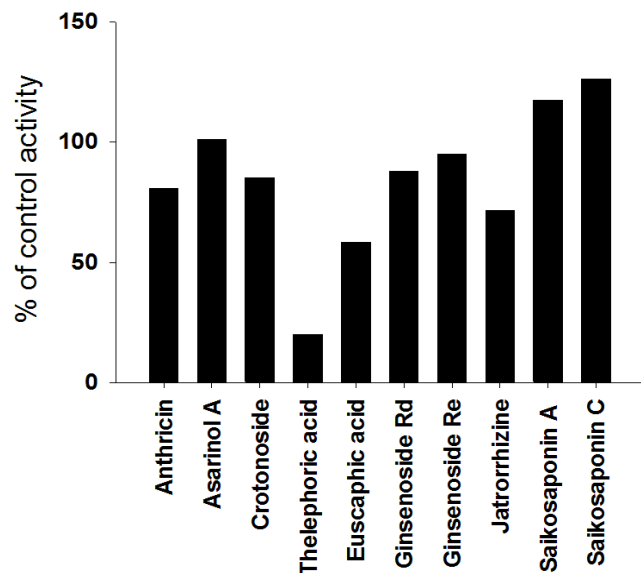

Fig. 3. Inhibitory effects of 10 natural products $(5 \mu \mathrm{g} / \mathrm{ml})$ on CYP 2J2-mediated astemizole $O$-demethylation activity. Pooled human liver microsomes $(0.1 \mathrm{mg} / \mathrm{ml}, \mathrm{H} 161)$ were incubated with $1 \mu \mathrm{M}$ astemizole in the absence or presence of various natural products at $37^{\circ} \mathrm{C}$ for $20 \mathrm{~min}$. Data shown are averages of remaining activity relative to the control metabolite formation rate estimated from triplicate experiments. 

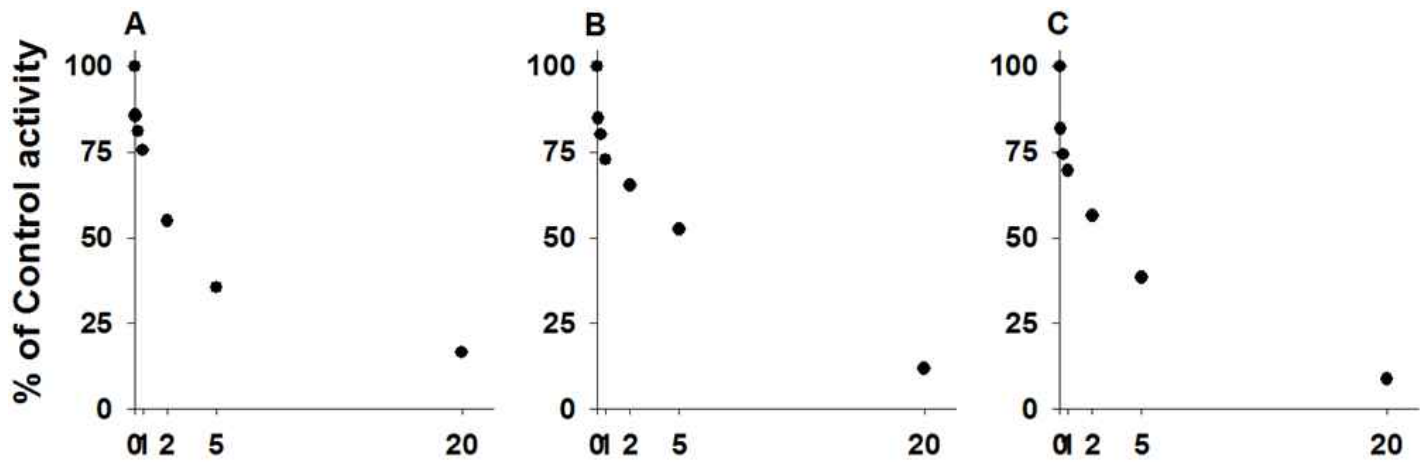

Thelephoric acid $(\mu \mathrm{M})$

Fig. 4. Inhibitory effects of thelephoric acid on CYP2J2-mediated astemizole $O$-demethylation (A), terfenadine hydroxylation (B), and ebastine hydroxylation $(\mathrm{C})$ activities. The data are the average of triplicate experiments. Pooled human liver microsomes $(0.1 \mathrm{mg} / \mathrm{ml}, \mathrm{H} 161)$ were incubated with astemizole $(1 \mu \mathrm{M})$, ebastine $(1 \mu \mathrm{M})$ or terfenadine $(5 \mu \mathrm{M})$ in the absence or presence of various concentrations of thelephoric acid $(0-20 \mu \mathrm{M})$ at $37^{\circ} \mathrm{C}$ for $20 \mathrm{~min}$. The activity was calculated at the percentage of control sample activity and plotted versus the thelephoric acid concentration. Each data point is the average of triplicate experiments.

Table 2. Effects of thelephoric acid on CYP2J2 activities in human liver microsomes

\begin{tabular}{llc}
\hline Substrate & \multicolumn{1}{c}{ Enzyme activity } & $\mathrm{IC}_{50}(\mu \mathrm{M})^{\mathrm{a}}$ \\
\hline Astemizole & Astemizole O-demethylation & 3.23 \\
Ebastine & Ebastine hydroxylation & 5.32 \\
Terfenadine & Terfenadine hydroxylation & 3.27 \\
\hline
\end{tabular}

${ }^{a}$ Averages of triplicate determinations $(n F 3)$.

The values are estimated from nonlinear least regression analysis using WinNonlin.

본 연구 결과, thelephoric acid가 CYP2J2의 기질 약물인 astemizole, ebastine 및 terfenadine의 대사를 보편적으로 저해하 는 것으로 나타났다. 따라서, thelephoric acid 는 종양세포에 선택적으로 과발현되어 있는 CYP2J2 단백을 표적으로 하는 선택적 저해제로 작용할 것으로 판단된다.

최근 terfenadine 유도체들이 세포사멸 촉진 및 종양 세포 의 성장 억제 등과 같은 기전을 통하여 표적 항암제 후보물질 로 사용될 수 있다는 결과가 보고되어 있다. 따라서 본 연구를 통하여 CYP2J2 저해능이 발견된 thelephoric acid의 경우에도, 유사한 골격을 가진 화합물 합성을 통한 구조-활성 상관성 연 구를 통하여 CYP2J2 효소 활성 저해능이 우수한 유효물질의 발굴이 가능할 것으로 판단된다. 그러나, 이를 위해서는 상기 화합물에 대한 다른 CYP 동효소 활성 저해능 평가, 세포 독성 평가 및 종양세포 사멸 기전 등과 같은 추가 실험이 더 필요할 것이다.

\section{감사의 글}

본 연구에 사용된 천연물은 한국한방산업진훙원에서 분양 받아 사용하였으며 이에 감사드립니다.

\section{References}

1. Capdevila, J. H., Falck, J. R. and Harris, R. C. 2000. Cytochrome P450 and arachidonic acid bioactivation. Molecular and functional properties of the arachidonate monooxygenase. J Lipid Res 41, 163-181.

2. Chen, C., Li, G., Liao, W., Wu, J., Liu, L., Ma, D., Zhou, J., Elbekai, R. H., Edin, M. L., Zeldin, D. C. and Wang, D. W. 2009. Selective inhibitors of CYP2J2 related to terfenadine exhibit strong activity against human cancers in vitro and in vivo. J Pharmacol Exp Ther 329, 908-918.

3. Jiang, J. G., Chen, C. L., Card, J. W., Yang, S., Chen, J. X., Fu, X. N., Ning, Y. G., Xiao, X., Zeldin, D. C. and Wang, D. W. 2005. Cytochrome P450 2J2 promotes the neoplastic phenotype of carcinoma cells and is up-regulated in human tumors. Cancer Res 65, 4707-4715.

4. Jiang, J. G., Fu, X. N., Chen, C. L. and Wang, D. W. 2009. Expression of cytochrome $\mathrm{P} 450$ arachidonic acid epoxygenase 2J2 in human tumor tissues and cell lines. Ai Zheng 28, 93-96.

5. Jiang, J. G., Ning, Y. G., Chen, C., Ma, D., Liu, Z. J., Yang, S., Zhou, J., Xiao, X., Zhang, X. A., Edin, M. L., Card, J. W., Wang, J., Zeldin, D. C. and Wang, D. W. 2007. Cytochrome p450 epoxygenase promotes human cancer metastasis. Cancer Res 67, 6665-6674.

6. Lafite, P., Andre, F., Zeldin, D. C., Dansette, P. M. and Mansuy, D. 2007. Unusual regioselectivity and active site topology of human cytochrome P450 2J2. Biochemistry 46, 10237-10247.

7. Lafite, P., Dijols, S., Buisson, D., Macherey, A. C., Zeldin, D. C., Dansette, P. M. and Mansuy, D. 2006. Design and synthesis of selective, high-affinity inhibitors of human cytochrome P450 2J2. Bioorg Med Chem Lett 16, 2777-2780.

8. Lee, C. A., Neul, D., Clouser-Roche, A., Dalvie, D., Wester, M. R., Jiang, Y., Jones, J. P., 3rd, Freiwald, S., Zientek, M. 
and Totah, R. A. 2010. Identification of novel substrates for human cytochrome P450 2J2. Drug Metab Dispos 38, 347-356.

9. Lee, S. S., Jeong, H. E., Liu, K. H., Ryu, J. Y., Moon, T., Yoon, C. N., Oh, S. J., Yun, C. H. and Shin, J. G. 2005. Identification and functional characterization of novel CYP2J2 variants: G312R variant causes loss of enzyme catalytic activity. Pharmacogenet Genomics 15, 105-113.

10. Liu, K.-H. 2011. Screening of potential anticancer compounds from marketed drugs: aripiprazole, haloperidol, miconazole, and terfenadine inhibit cytochrome P450 2J2. J Life Sci 21, 1558-1564.

11. Liu, K. H., Kim, M. G., Lee, D. J., Yoon, Y. J., Kim, M. J., Shon, J. H., Choi, C. S., Choi, Y. K., Desta, Z. and Shin, J. G. 2006. Characterization of ebastine, hydroxyebastine, and carebastine metabolism by human liver microsomes and expressed cytochrome P450 enzymes: major roles for CYP2J2 and CYP3A. Drug Metab Dispos 34, 1793-1797.

12. Makita, K., Takahashi, K., Karara, A., Jacobson, H. R., Falck, J. R. and Capdevila, J. H. 1994. Experimental and/or genetically controlled alterations of the renal microsomal cytochrome P450 epoxygenase induce hypertension in rats fed a high salt diet. $J$ Clin Invest 94, 2414-2420.

13. Matsumoto, S., Hirama, T., Kim, H. J., Nagata, K. and Yamazoe, Y. 2003. In vitro inhibition of human small intestinal and liver microsomal astemizole O-demethylation: different contribution of CYP2J2 in the small intestine and liver. Xenobiotica 33, 615-623.

14. Node, K., Huo, Y., Ruan, X., Yang, B., Spiecker, M., Ley, K., Zeldin, D. C. and Liao, J. K. 1999. Anti-inflammatory properties of cytochrome $\mathrm{P} 450$ epoxygenase-derived eicosanoids. Science 285, 1276-1279.

15. Park, J.-H., Wu, Q., Yoo, K.-H., Yong, H.-I., Cho, S.-M., Chung, I.-S. and Baek, N.-I. 2011. Cytotoxic effect of flavonoids from the roots of glycyrrhiza uralensis on human cancer cell lines. J Appl Biol Chem 54, 67-70.

16. Pfister, S. L. and Campbell, W. B. 1996. Contribution of arachidonic acid metabolites to reduced norepinephrine-induced contractions in hypercholesterolemic rabbit aortas. $J$ Cardiovasc Pharmacol 28, 784-791.

17. Pfister, S. L., Spitzbarth, N., Zeldin, D. C., Lafite, P., Mansuy, D. and Campbell, W. B. 2003. Rabbit aorta converts
15-HPETE to trihydroxyeicosatrienoic acids: potential role of cytochrome P450. Arch Biochem Biophys 420, 142-152.

18. Pucci, L., Lucchesi, D., Chirulli, V., Penno, G., Johansson, I., Gervasi, P., Del Prato, S. and Longo, V. 2003. Cytochrome P450 2J2 polymorphism in healthy Caucasians and those with diabetes mellitus. Am J Pharmacogenomics 3, 355-358.

19. Scarborough, P. E., Ma, J., Qu, W. and Zeldin, D. C. 1999. P450 subfamily CYP2J and their role in the bioactivation of arachidonic acid in extrahepatic tissues. Drug Metab ReV 31, 205-234.

20. Shon, J. H., Yeo, C. W., Liu, K. H., Lee, S. S., Cha, I. J. and Shin, J. G. 2010. Itraconazole and rifampin alter significantly the disposition and antihistamine effect of ebastine and its metabolites in healthy participants. J Clin Pharmacol 50, 195-204.

21. Sun, J., Sui, X., Bradbury, J. A., Zeldin, D. C., Conte, M. S. and Liao, J. K. 2002. Inhibition of vascular smooth muscle cell migration by cytochrome p450 epoxygenase-derived eicosanoids. Circ Res 90, 1020-1027.

22. Wang, L., Zhang, D., Raghavan, N., Yao, M., Ma, L., Frost, C. E., Maxwell, B. D., Chen, S. Y., He, K., Goosen, T. C., Humphreys, W. G. and Grossman, S. J. 2010. In vitro assessment of metabolic drug-drug interaction potential of apixaban through cytochrome P450 phenotyping, inhibition, and induction studies. Drug Metab Dispos 38, 448-458.

23. Wu, S., Moomaw, C. R., Tomer, K. B., Falck, J. R. and Zeldin, D. C. 1996. Molecular cloning and expression of CYP2J2, a human cytochrome P450 arachidonic acid epoxygenase highly expressed in heart. J Biol Chem 271, 3460-3468.

24. Yoon, Y. J. and Liu, K. H. 2011. Potential of hydroxyebastine and terfenadine alcohol to inhibit the human cytochrome P450 2J2 isoform. J Korean Soc Appl Biol Chem 54, 659-666.

25. Yu, Z., Huse, L. M., Adler, P., Graham, L., Ma, J., Zeldin, D. C. and Kroetz, D. L. 2000. Increased CYP2J expression and epoxyeicosatrienoic acid formation in spontaneously hypertensive rat kidney. Mol Pharmacol 57, 1011-1020.

26. Zeldin, D. C., Foley, J., Boyle, J. E., Moomaw, C. R., Tomer, K. B., Parker, C., Steenbergen, C. and Wu, S. 1997. Predominant expression of an arachidonate epoxygenase in islets of Langerhans cells in human and rat pancreas. Endocrinology $138,1338-1346$ 
초록 : Thelephoric acid의 CYP2J2 효소 활성 저해제 평가

오철학·이보람 · 송경식 · 류광현*

(경북대학교 약학대학 약학과)

CYP2J2 효소는 간외의 조직에 존재 하는 효소로써, 주로 심혈관계에 발현되어 있다. CYP2J2는 내인성 대사체 및 여러 치료 약물들의 대사에 중요한 작용을 하고 있다. 또한 CYP2J2는 인체의 종양조직이나 종양 세포주에서 과발현되어 있어, 종양 치료를 위한 새로운 표적이 되고 있다. 본 연구에서는 천연물 10 종을 대상으로 시토크롬 $2 J 2$ 동효소에 저해능을 가지는 화합물을 발굴하고자 하였다. 10종의 천연물 중 thelephoric acid는 CYP2J2에 의해 매개되는 에바스틴 $\left(\mathrm{IC}_{50}=5.32 \mu \mathrm{M}\right)$, 아스테미졸 $\left(\mathrm{IC}_{50}=3.23 \mu \mathrm{M}\right)$ 및 터페나딘 $\left(\mathrm{IC}_{50}=3.27 \mu \mathrm{M}\right)$ 대사를 강력하게 저해하 였다. 향후, 이 약물을 대상으로 한 항암 활성 평가가 필요할 것으로 판단된다. 